\title{
Balance y perspectivas de la interpretación normativa del Ministerio de Economía y Finanzas en el marco de su rol rector del Sistema Nacional de Promoción de la Inversión Privada
}

\author{
Milagros Maraví Sumar ${ }^{(*)}$ \\ Abogada por la Pontificia Universidad Católica del Perú. \\ Máster en Administración Pública por el Instituto Ortega y Gasset, adscrito \\ a la Universidad Complutense de Madrid.
}

SUMARIO:

I. Introducción.

II. Evaluación de las interpretaciones del MEF.

III. ¿Ha sido conveniente la emisión de estas opiniones que no correspondían?

IV. Opiniones técnicas vinculantes de la DGPPIP sobre el Decreto Legislativo 1362 y su Reglamento.

1. Naturaleza del cofinanciamiento.

2. Pertinencia de las opiniones previas a que se refiere el Decreto Legislativo 1362.

3. Proceso de modificación contractual y criterios para su procedencia.

4. Naturaleza de las inversiones adicionales en un contrato de APP.

5. Criterio para calificar a una entidad pública como titular de un proyecto de APP.

6. Cesión de posición contractual en un contrato de concesión.

7. Naturaleza y trato normativo de la cláusula anticorrupción.

8. Modificaciones a la Iniciativa Privada y al cómputo de plazos previos a la opinión de relevancia.

9. Las funciones de Proinversión ante el encargo del Proceso de Promoción de un proyecto aún no incorporado en el Informe Multianual de Inversiones en Asociaciones Público Privadas.

10. Los alcances del informe previo de la Contraloría General de la República en las fases de estructuración y transacción de un contrato de APP.

V. Conclusiones.

(*) Expreso mi reconocimiento por la invalorable colaboración en esta investigación a los practicantes del Área de Derecho Administrativo del Estudio Rubio, Leguía, Normand: Braylyn Paredes —Pontificia Universidad Católica del Perú-, Nahomi More — Universidad Nacional Mayor de San Marcos_y Roy Aguilera — Universidad de Piura-. 


\title{
RESUMEN:
}

En el presente trabajo se realiza un análisis, desde una perspectiva crítica y práctica, de la interpretación normativa realizada por el Ministerio de Economía y Finanzas en virtud de su rol rector del Sistema Nacional de Promoción de la Inversión Privada en relación a la normativa actual de Asociaciones Público Privadas. De ello, se determinó que dichas interpretaciones normativas no resultan ser oportunas dada la centralización de decisiones en el ente rector; pues debe primar la autonomía de las entidades al emitir decisiones de gestión respecto de los proyectos de su competencia.

Palabras clave: Asociaciones Público-Privadas, Sistema Nacional de Promoción de la Inversión Privada, interpretación normativa, opiniones vinculantes, principio de colaboración entre entidades.

\begin{abstract}
:
This article develops an analysis from a critical and practical perspective, of the normative interpretation that the peruvian Ministry of Economy has regarding its governing role in the National System for the Promotion of Private Investment in relation to the current legislation for public-private partnerships. From the analysis it was determined that said normative interpretations are inadequate due to the centralization of decisions in the governing entity, since the autonomy of entities should prevail when undertaking management decisions on projects of their jurisdiction.

Keywords: Public-Private Partnerships, National System for the Promotion of Private Investment, normative interpretation, binding opinions, principle of collaboration among entities.
\end{abstract}

\section{INTRODUCCIÓN}

Con el Decreto Legislativo 1224', se creó el Sistema Nacional de Promoción de la inversión Privada - SNPIP, de carácter funcional, cuyo ente rector es el Ministerio de Economía y Finanzas - MEF, a través de la Dirección General de Política de Promoción de la Inversión Privada DGPPIP. La vigente normativa de Asociaciones Público Privadas - APP, a través del Decreto Legislativo 1362 —en adelante, "DL 1362"2 o "Ley de APP"- mantiene esta misma configuración.

Como ya expresamos en un artículo sobre el rol rector del MEF en el $2018^{3}$ una de las funciones que asume el MEF como rector es la de "emitir opinión exclusiva y excluyente con carácter vinculante sobre el alcance de las normas del SNPIP de su competencia". Así, el artículo 5.4, numeral 2 del DL 1362 expresa que la DGPPIP es competente para emitir opinión vinculante, exclusiva y excluyente, en el ámbito administrativo, sobre la interpretación y la aplicación de las normas del SNPIP. El Reglamento del DL 1362 precisa que estas opiniones son publicadas en el portal institucional del MEF —artículo 9.1.4-.

La Resolución Directoral N 001-2016-EF/68.014 aprueba los Criterios Generales para la atención de Consultas Técnico Normativas en materia de APP y Proyectos en Activos. En dicha norma, el MEF ha precisado que las consultas que se for-

1. Decreto Legislativo del Marco de Promoción de la Inversión Privada mediante Asociaciones Público Privadas y Proyectos en Activos, publicado el 25 de setiembre de 2015, en el Diario Oficial El Peruano.

2. Decreto Legislativo que regula la Promoción de la Inversión Privada mediante Asociaciones Público Privadas y Proyectos en Activos, publicado el 23 de julio de 2018, en el Diario Oficial El Peruano.

3. Milagros Maraví Sumar. "El Rol Rector del Ministerio de Economía y Finanzas en las APPs", en El Derecho Administrativo como instrumento al Servicio del Ciudadano, Memorias del Octavo Congreso de Derecho Administrativo, (Lima: Palestra, 2018): 247-268.

4. Publicada en el Diario Oficial El Peruano el 17 de marzo de 2016. 
mulen, deben cumplir los siguientes criterios generales:

a) Estar vinculadas a determinar el alcance e interpretación de las normas del SNPIP en materia de APP y Proyectos en Activos - PA.

b) Deben referirse a asuntos generales sin hacer referencia a asuntos, casos, proyectos o contratos específicos.

c) Toda consulta debe adjuntar los respectivos informes técnico y legal, de las áreas competentes en los que se indique la duda interpretativa o alcance respecto de un determinado dispositivo legal del SNPIP en materia de APP y PA respecto de la cual se solicita absolver la consulta técnico normativa, precisando claramente la posición del área consultante y su sustento respectivo.

Si bien el último punto podría indicar que las consultas solo pueden ser formuladas por personas jurídicas o entidades públicas, no existe limitación alguna respecto de la legitimación para consulta, que es amplia e incluye a cualquier persona natural o jurídica o entidad pública. Adicionalmente, se estableció que el plazo de atención para dichas consultas es de treinta -30-días hábiles.

A la fecha de nuestro artículo del 2018 sobre la materia, el MEF había emitido más de treinta -30 - respuestas a consultas técnico normativas y, como concluíamos,

"El efecto de la creación del SNPIP ha sido poner de rector a una entidad que también participa al menos en tres fases del proceso de promoción de la inversión privada emitiendo opinión previa vinculante y, por eso, las demás entidades integrantes del SNPIP han optado por consultarle a la DGPPIP, a través de la emisión de opiniones vinculantes, aspectos que en su mayoría son de interpretación para adop- tar decisiones de gestión en el marco de procesos de promoción de la inversión privada."

Lo anterior se presenta sin perjuicio de que la Resolución Directoral Nº 001-2016-EF/68.01 ha precisado que "2.3 Las opiniones que se emitan en el marco de la presente Resolución Directoral ADMINISTRATIVo no determinan responsabilidades ni pueden considerarse como Opinión Previa (...)".

Han pasado dos años desde esa publicación y es conveniente evaluar, por un lado, si esta tendencia advertida ha continuado y, por el otro, cuál ha sido el impacto en el SNPIP debido a su ejercicio.

\section{EVALUACIÓN DE LAS INTERPRETACIONES DEL MEF}

De esa manera, desde el 18 de enero de 2017 y hasta el 16 de junio de 2020, se han emitido las siguientes respuestas a solicitudes de interpretación vinculante:

\section{Cuadro № 1}

\section{Respuestas a solicitudes de interpretación vinculante}

\begin{tabular}{c|c} 
Año & $\begin{array}{c}\text { Número de opiniones } \\
\text { vinculantes }\end{array}$ \\
\hline 2017 & 47 \\
\hline 2018 & 15 \\
\hline 2019 & 25 \\
\hline 2020 & 11 \\
\hline Total & $\mathbf{9 8}$
\end{tabular}

En nuestro texto del 2018, señalábamos que el MEF emite, a través de la DGPPIP, opinión técnica vinculante en etapas decisivas del proceso de promoción de la inversión privada y así asegura la legalidad de las APP, sin requerirse de su participación como rector a través de la misma DGPPIP. ${ }^{6}$

5. Maraví, “El Rol Rectos del Ministerio.... 247-268.

6. Ibíd. 
Asimismo, en ese texto comentábamos algunas de las opiniones vinculantes controversiales emitidas por el MEF referidas a la opinión previa de la Contraloría General de la República y respecto del procedimiento de modificación contractual. ${ }^{7}$

En este trabajo nos referiremos y analizaremos los oficios que responden a consultas técnico normativas respecto del DL 1362 y su Reglamento. De las 98 antes aludidas, solo 34 son respuestas a solicitudes de interpretaciones vinculantes de esta norma y las demás se refieren a la normativa previamente vigente.

De esas 34, 30 hacen referencia a artículos puntuales del Texto Único Ordenado del DL 1362 o su Reglamento para ser objeto de "precisión" "aclaración" o "definición", tal y como se señala en el Anexo 1 del presente trabajo.

Sin embargo, no podemos considerar que todas esas 30 opiniones que hacen referencia a artículos de la Ley, o del Reglamento de la Ley de APP, constituyen opinión técnica vinculante.

Solo 15 emiten opinión técnica vinculante, ya que otras 15 se emiten, aunque no correspondan, en función del "principio de colaboración entre entidades", sustentadas en el "principio de adecuado servicio al ciudadano" y en consideración al "principio de predictibilidad".

En ninguno de estos últimos supuestos la interpretación realizada por el MEF es vinculante ni se emite en el marco de su competencia. Sin embargo, esas opiniones no vinculantes son usualmente seguidas por las entidades públicas en la medida que la DGPPIP emite opinión previa en al menos tres fases de las APP y seguirá tal criterio al evaluar los proyectos, sin mencionar el cuestionamiento que podrían enfrentar ante una interpretación divergente al rector por parte del sistema nacional de control.

En efecto, existen casos como, por ejemplo, el del Oficio $\mathrm{N}^{\circ}$ 063-2020 EF/68.02 —y su informe adjunto $\mathrm{N}^{\circ}$ 069-2020-EF/68.02 - que contienen una interpretación del artículo 4, referido a los principios de: "Valor por Dinero" —artículo 4.2.1.- y "Adecuada distribución de riesgos" —artículo 4.2.2. - y, a los artículos 37 y 11 del Reglamento del la Ley de APP que aluden a la "Fuerza Mayor" y el "equilibrio económico financiero". Sin embargo, en las conclusiones del Informe que acompaña al Oficio, se afirma que "3.1. La presente consulta normativa no cumple con los criterios establecidos en la normativa para que la DGPPIP emita opinión en su calidad de Ente Rector". Ello quiere decir que el ente rector del SNPIP en este supuesto emitió opinión no vinculante, lo cual no está previsto en el marco de su competencia.

Sin embargo, como era previsible, esta opinión fue en su momento usada por la entidad consultante como respaldo para responder las solicitudes de suspensión de plazos por fuerza mayor.

En efecto, mediante Oficio $\mathrm{N}^{\circ}$ 063-2020EF/68.02 e Informe Nº69-2020-EF/68.02 la DGPPIP ha precisado que:

"2.13. (...) el riesgo de fuerza mayor se materializa ante:

- La ocurrencia de un evento inesperado.

- Fuera de control de las partes.

- Que impida la ejecución de la obligación, de acuerdo a lo establecido en el Contrato de APP.

- Según el Código Civil, además de cumplir las condiciones de extraordinario, imprevisible e irresistible, debe existir un nexo causal entre el evento adverso y la imposibilidad de cumplir una o más obligaciones.

2.14. Por su parte, el riesgo regulatorio o normativo se configura cuando ocurre un tipo de cambio normativo que impacta de manera significativa en el nivel de ingresos o costos del proyecto. El origen de ambos riesgos se encuentra pues en eventos distintos, a los que 
se le aplican mecanismos distintos de mitigación, por lo que los efectos de ocurrencia de uno no podrán ser equiparables a la del otro."

A contrapelo de esta opinión, tal y como la misma DGPPIP ha reconocido en la Resolución Directoral $\mathrm{N}^{\circ}$ 003-2020-EF/68.01 que aprueba los Lineamientos para la respuesta del Estado frente a los potenciales impactos generados por la pandemia del COVID-19 en proyectos de Asociación Público Privada, son causales de fuerza mayor tanto la pandemia de la COVID-19 como las medidas que se dictaron para enfrentarla que implicaron diversas medidas de restricción tales como el cierre de fronteras, el aislamiento social obligatorio y el cumplimiento de protocolos de limpieza, desinfección y distanciamiento social.

\section{Como señala Shoschana Zusman:}

"( $x$ ) Lo lógico y normal es que, ante un evento general de fuerza mayor -un terremoto o una pandemia- el Estado expida algún tipo de regulación, decisión u orden gubernamental (estado de emergencia, toque de queda, aforo, cierre temporal de negocios, etc.). No es posible, en términos reales, que el Estado permanezca impasible ante tales acontecimientos. Siempre se emitirá normativa u órdenes gubernamentales en relación al evento de fuerza mayor, que normalmente es un acontecimiento general. Si se interpretara, entonces, que si se ha emitido una norma u orden gubernamental, deja de ser de aplicación el concepto de fuerza mayor, éste perdería prácticamente su contenido porque -ya lo hemos dicho- siempre se expedirán normas, órdenes o decisiones de la autoridad que la abordará. Según esta tesis, entonces, se impedirá en todos los casos, aplicar las normas y lineamientos sobre si fueran un concepto de fuerza mayor. Con lo cual la excluyen de su carácter de vínculo causal.

(xi) En otras palabras, la emisión de normas, decisiones gubernamentales $u$ otras, siempre existirá y siempre será posterior al evento de fuerza mayor o, al menos, simultáneo, al in- ADMINISTRATIVo cumplimiento. Por eso es que decíamos en el literal anterior que, si se asume de manera literalista que, únicamente las normas emitidas en ocasión del COVID-19, constituyen el vínculo causal entre el hecho y el resultado, jamás podría invocarse la fuerza mayor.

\section{(...)}

(xiii) La separación de dos eventos estrechamente unidos, como son la pandemia y la normativa expedida al respecto, es artificial. De no haberse producido la pandemia, la normativa no se habría expedido. Separarlos implicaría también, admitir que, si una persona se contagia, no es por la pandemia, sino por el agente que se lo transmitió."18

En base a ello, entonces, serán causales de fuerza mayor y, de ser el caso, de equilibrio económico financiero.

Como explicamos en el texto "Covid 19 y la Fuerza Mayor" ${ }^{\prime \prime}$; la interpretación de este oficio y su informe era errada porque consideraba las normas dictadas por el Estado peruano en el contexto de la COVID-19, cuando es una causal de fuerza mayor indesligable de las normas dictadas a propósito de él.

¿Cuál es la razón aludida por la DGPPIP para emitir opinión aun cuando no corresponde? El punto 2.8 del Informe $\mathrm{N}^{\circ}$ 069-2020-EF/68.02 hace referencia al principio de colaboración entre entidades regulado en los artículos 87 a 90

8. Shoschana Zusman, "Informe que tuvo por objeto determinar si, en el contexto de la pandemia creada por el COVID 19, la causa del incumplimiento por parte de los concesionarios titulares de Contratos de Concesión de Asociaciones Público Privadas y de la suspensión de sus obligaciones, es la propia pandemia, la normativa que se expidió con ocasión de ésta, o ambas a la vez" (2020).

9. Milagros Maraví Sumar, “Covid 19 y la Fuerza Mayor”, Boletín AFIN 256, (2020): 14-15. 
del Texto Único Ordenado de la Ley del Procedimiento Administrativo General ${ }^{10}$; el cual justificaría afirmar que "(...) es posible realizar algunas precisiones de carácter general sobre el marco normativo vigente".

El ejemplo citado del Oficio $\mathrm{N}^{\circ}$ 063-2020 EF/68.02 y su Informe adjunto $N^{\circ}$ 069-2020$\mathrm{EF} / 68.02$ es un claro reflejo de los efectos no- civos de una opinión del rector que son tomadas como sustento posterior en trámites en los que ni debe ni tiene participación la DGPPIP ni como rector ni como emisor de opinión previa, como es las solicitudes de suspensión de plazos por caso fortuito o fuerza mayor.

Un supuesto similar se presenta en el Oficio $N^{\circ}$ 022-2020 e Informe $N^{\circ}$ 031-2020; que, en su

10. “Artículo 87.- Colaboración entre entidades

87.1 Las relaciones entre las entidades se rigen por el criterio de colaboración, sin que ello importe renuncia a la competencia propia señalada por ley.

87.2 En atención al criterio de colaboración las entidades deben:

87.2.1 Respetar el ejercicio de competencia de otras entidades, sin cuestionamientos fuera de los niveles institucionales. 87.2.2 Proporcionar directamente los datos e información que posean, sea cual fuere su naturaleza jurídica o posición institucional, a través de cualquier medio, sin más limitación que la establecida por la Constitución o la ley, para lo cual se propenderá a la interconexión de equipos de procesamiento electrónico de información, u otros medios similares. 87.2.3 Prestar en el ámbito propio la cooperación y asistencia activa que otras entidades puedan necesitar para el cumplimiento de sus propias funciones, salvo que les ocasione gastos elevados o ponga en peligro el cumplimiento de sus propias funciones.

87.2.4 Facilitar a las entidades los medios de prueba que se encuentren en su poder, cuando les sean solicitados para el mejor cumplimiento de sus deberes, salvo disposición legal en contrario.

87.2.5 Brindar una respuesta de manera gratuita y oportuna a las solicitudes de información formuladas por otra entidad pública en ejercicio de sus funciones.

87.3 En los procedimientos sujetos a silencio administrativo positivo el plazo para resolver quedará suspendido cuando una entidad requiera la colaboración de otra para que le proporcione la información prevista en los numerales 87.2.3 y 87.2.4, siempre que ésta sea indispensable para la resolución del procedimiento administrativo. El plazo de suspensión no podrá exceder el plazo dispuesto en el numeral 3 del artículo 143.

87.4 Cuando una entidad solicite la colaboración de otra entidad deberá notificar al administrado dentro de los 3 días siguientes de requerida la información."

"Artículo 88.- Medios de colaboración interinstitucional

88.1 Las entidades están facultadas para dar estabilidad a la colaboración interinstitucional mediante conferencias entre entidades vinculadas, convenios de colaboración u otros medios legalmente admisibles.

88.2 Las conferencias entre entidades vinculadas permiten a aquellas entidades que correspondan a una misma problemática administrativa, reunirse para intercambiar mecanismos de solución, propiciar la colaboración institucional en aspectos comunes específicos y constituir instancias de cooperación bilateral. Los acuerdos serán formalizados cuando ello lo amerite, mediante acuerdos suscritos por los representantes autorizados.

88.3. Por los convenios de colaboración, las entidades a través de sus representantes autorizados, celebran dentro de la ley acuerdos en el ámbito de su respectiva competencia, de naturaleza obligatoria para las partes y con cláusula expresa de libre adhesión y separación.

88.4 Las entidades pueden celebrar convenios con las instituciones del sector privado, siempre que con ello se logre el cumplimiento de su finalidad y no se vulnere normas de orden público."

"Artículo 89.- Ejecución de la colaboración entre autoridades

89.1 La procedencia de la colaboración solicitada es regulada conforme a las normas propias de la autoridad solicitante, pero su cumplimiento es regido por las normas propias de la autoridad solicitada.

89.2 La autoridad solicitante de la colaboración responde exclusivamente por la legalidad de lo solicitado y por el empleo de sus resultados. La autoridad solicitada responde de la ejecución de la colaboración efectuada."

"Artículo 90.- Costas de la colaboración

90.1 La solicitud de colaboración no genera el pago de tasas, derechos administrativos o de cualquier otro concepto que implique pago alguno, entre entidades de la administración pública

90.2 A petición de la autoridad solicitada, la autoridad solicitante de otra entidad tendrá que pagar a ésta los gastos efectivos realizados cuando las acciones se encuentren fuera del ámbito de actividad ordinaria de la entidad." 
punto 2.8 señala que "(...) no corresponde que las mencionadas referencias sean objeto de una interpretación técnica normativa por parte de la DGPPIP, en el marco de lo dispuesto en el numeral 2 del párrafo 5.4 del artículo 5 del Decreto Legislativo No 1362 (...)". Sin perjuicio de que concluye en el numeral 3.1 reiterando que no corresponde que se emita opinión vinculante, en función del principio de colaboración -numeral 2.9se explaya en responder la consulta para precisar que "entre las otras modalidades permitidas por la ley para el desarrollo de PA, se encuentra la servidumbre, regulada en los artículos 1035 y siguientes del Código Civil, incluyendo la servidumbre legal de paso".

Dicha respuesta determinó a su vez la respuesta de la entidad consultante en el sentido definido por la DGPPIP, aun cuando la figura de PA no es la única ni la más eficiente para establecer servidumbres de paso. Así lo ha precisado la misma DGPPIP ante una consulta sobre el mismo caso efectuada con posterioridad que define que entre las figuras a las que puede recurrirse para PA previstas en el artículo 49.2, numeral 2, está la servidumbre legal de paso regulada en los artículos 1035 y siguientes del Código Civil y que "(...) es la entidad pública titular del proyecto la única responsable de sustentar y validar que un proyecto pueda ser desarrollado bajo la modalidad de PA, sobre la base de la normativa específica, lo que incluye la facultad de disponer de sus activos" - Informe N 031-2020-EF/68.02. numeral 2.9, in fine-.

Esto debe entenderse como que no excluye otras vías legales de establecimiento de servidumbre legal prevista en el marco normativo peruano.

Existe asimismo otro supuesto de respuestas a solicitudes de emisión de opinión vinculante en las que se ha definido que se emiten en virtud del mismo principio de colaboración. Por ejemplo, el Oficio $N^{\circ}$ 061-2020 y su Informe $\mathrm{N}^{\circ}$ 0662020 que expresamente señala en su punto 2.1 que "Por lo tanto, no corresponde que las mencionadas referencias sean objeto de una interpretación técnica normativa por parte de la DGPPIP, en el marco de lo dispuesto en el numeral 2 del párrafo 5.4. del artículo 5 del Decreto Legislativo No 1362." A renglón seguido, en el punto 2.12 se dispone que "Sin perjuicio de lo antes mencionado, y en razón del principio de colaboración entre entidades, se procede a brindar las siguientes precisiones de carácter general respecto de las materias consultadas", procediendo acto seguido a ADMINISTRATIVO definir y diferenciar, con ejemplos incluidos, los supuestos de "ejecución contractual" de aquellos de "modificación contractual".

Es el caso asimismo del Oficio $\mathrm{N}^{\circ}$ 019-2019 -e Informe $\mathrm{N}^{\circ} 190-2019$ - en los que en el punto 2.5 señala que la solicitud no cumple los requisitos para ser atendida, pero, en virtud del principio de colaboración -apartado 2.6- "(...) procederá a atender la consulta técnica en cuestión (...)".

Mención aparte merece un caso de interpretación "de oficio" —Oficio N ${ }^{\circ}$ 004-2020 y su Informe $\mathrm{N}^{\circ}$ 024-2020 - ante una comunicación de la Contraloría General de la República que cuestiona un Oficio de interpretación previo - $\mathrm{N}^{\circ} 363-2019-$ del MEF. En este Oficio - $\mathrm{N}^{\circ}$ 004-2020 — se realiza "de oficio" la interpretación del concepto de cofinanciamiento para precisar que:

\begin{abstract}
"26. Si se pretendiera calificar como "cofinanciamiento" a aquellos pagos a favor de terceros que no tienen parte en la relación jurídica contractual, se estaría extendiendo indebidamente el concepto de cofinanciamiento, toda vez que dicho concepto requiere que se trate de pagos realizados a la contraparte del Estado en un contrato de APP, conforme a lo dispuesto en el artículo 24 del DLEG 1362.
\end{abstract}

27. Tal podría ser el caso del pago que realiza directamente la entidad pública titular del proyecto a favor de la supervisión en un contrato autofinanciado, sin que medie participación del inversionista. En este caso, dicho pago no podrá ser considerado cofinanciamiento."

Las razones por las que no proceden las interpretaciones vinculantes solicitadas están principalmente ligadas a que en ellas se alude a un caso concreto. Por ejemplo, es el caso del Oficio .

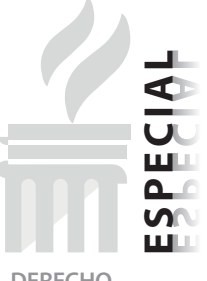


$\mathrm{N}^{\circ}$ 061-2020-EF/68.02 - Informe $\mathrm{N}^{\circ}$ 066-2020$\mathrm{EF} / 68.02-$ :

"2.10. En tal sentido, se advierte que la consulta formulada por ESSALUD se encuentra vinculada a un caso concreto, que real o hipotético, contienen referencias a proyectos $y$ contratos específicos.

2.11. Por lo tanto, no corresponde que las mencionadas referencias sean objeto de una interpretación técnica normativa por parte de la DGPPIP, en el marco de lo dispuesto en el numeral 2 del párrafo 5.4 del artículo 5 del Decreto Legislativo $N^{\circ} 1362 . "$

Eso implica que esas consultas, la mayoría de las efectuadas y respondidas por el MEF, se tratan de entidades públicas que ante casos concretos efectúan consultas al MEF para adoptar decisiones de gestión que, según el tenor de las mismas, "2.17. (...) las entidades públicas son las responsables de gestionar y administrar los contratos de APP bajo su titularidad (...)".

\section{III. ¿HA SIDO CONVENIENTE LA EMISIÓN DE ESTAS OPINIONES QUE NO CORRESPON- DÍAN?}

Desde nuestro punto de vista, en proyectos en curso, en los cuales la DGPPIP emitiría opinión en una etapa del mismo, no debería pronunciarse. Por ejemplo, en lo referido a una posible celebración de adendas.

Tampoco cuando se trata de decisiones de gestión que deben ser adoptadas por cada entidad. Creemos que no es oportuno que el MEF emita opinión en dichos casos pues dilata las decisiones y las centraliza en los hechos en el rector. Es conveniente la autonomía de las entidades al emitir decisiones respecto de los proyectos de su competencia. En todo caso, la DGPPIP debería haber rechazado de plano las consultas referidas a casos específicos o encauzado la consulta e interpretar alguna norma en particular del DL 1362 o su Reglamento.

Además, como hemos mencionado, esas opiniones son tomadas por el sistema nacional de control como parámetro de evaluación de las entidades.

\section{OPINIONES TÉCNICAS VINCULANTES DE LA DGPPIP SOBRE EL DECRETO LEGISLA- TIVO 1362 Y SU REGLAMENTO}

Las opiniones técnicas vinculantes emitidas dentro del marco de su competencia por la DGPPIP y que deben ser seguidas obligatoriamente por todos los actores de las APP en todas sus etapas, son las siguientes:

(a) Naturaleza del cofinanciamiento -Oficios $\mathrm{N}^{\circ}$ 048-2018-EF/68.02 y 004-2020$\mathrm{EF} / 68.02$ -

(b) Pertinencia de las opiniones previas a que se refiere el Decreto Legislativo 1362 Oficio N ${ }^{\circ}$ 004-2019-EF/68.02-.

(c) Procedimiento de modificación contractual y criterios para su procedencia -Oficios $\mathrm{N}^{\circ}$ 005-2019-EF/68.02, 012-2019-EF/68.02, 016-2019-EF/68.02, 006-2019-EF-68.02 у 021-2020-EF/68.02).

(d) Naturaleza de las inversiones adicionales —Oficio N 041-2019-EF/68.02-.

(e) Criterio para calificar a las entidades públicas como titular de un proyecto de Asociación Público Privada -Oficio Nº 015-2019EF/68.02-.

(f) Cesión de posición contractual en contratos de concesión -Oficio N N 117-2019$\mathrm{EF} / 68.02$-.

(g) Naturaleza y trato normativo de la cláusula anticorrupción -Oficio N 010-2019$\mathrm{EF} / 68.02-$ -

(h) Modificaciones a la Iniciativa Privada y al cómputo de plazos previos a la opinión de relevancia —Oficio $\mathrm{N}^{\circ}$ 022-2019$\mathrm{EF} / 68.02-$ -

(i) Las funciones de Proinversión ante el encargo del Proceso de Promoción de un 
proyecto aún no incorporado en el Informe Multianual de Inversiones en Asociaciones Público Privadas -Oficio $N^{\circ} 025$ 2019-EF/68.02-.

(j) Los alcances del informe previo de la Contraloría General de la República en las fases de estructuración y transacción de un contrato de APP —Oficio $N^{\circ}$ 034-2019$\mathrm{EF} / 68.02$ -

\section{Naturaleza del cofinanciamiento.}

\section{Opiniones vinculantes: Oficios $\mathrm{N}^{\circ}$ 048-2018- $E F / 68.02$ y 004-2020-EF/68.02. ${ }^{11}$}

De acuerdo con el artículo 22 del Decreto Legislativo 1362, las APP se dividen en dos grupos: autofinanciadas y cofinanciadas.

Se considera que una APP es cofinanciada cuando estas requieren otorgamiento o contratación de garantías financieras o no financieras que tienen gran probabilidad de requerir cofinanciamiento por parte del Estado.

Este tipo de APP no tiene capacidad propia de generación de ingresos, por lo que los pagos son realizados utilizando fondos públicos, total o parcialmente, a cargo de la entidad titular del proyecto para cubrir las obligaciones establecidas en el contrato de APP.

El artículo 55 del Reglamento dispone que no constituye cofinanciamiento: la cesión en uso o usufructo de cualquier infraestructura o inmueble preexistente, los gastos derivados de las adquisiciones y expropiaciones de inmuebles para la ejecución de infraestructura pública o reubicaciones ni los pagos de peajes, tarifas, precios cobrados directamente a los usuarios o indirectamente a través de empresas para su posterior entrega al inversionista en el marco del contrato de APP.
A propósito del Oficio $N^{\circ}$ 049-2019-EF/68.02, en el que se expresaba de manera no vinculante, entre otros temas, que la contratación de un supervisor responde al cumplimiento de disposiciones normativas aplicables a todos los contratos de APP, por lo que la contratación y correspondiente pago de supervisión
en este tipo de contratos no constituye cofinanciamiento, se emitió en el año 2020 por medio del Oficio $N^{\circ}$ 004-2020-EF/68.02 una opinión, esta vez vinculante, en la que el MEF señala lo siguiente:

\section{"Calificar como "cofinanciamiento" los pagos realizados a favor de terceros que no tienen la calidad de parte, como lo es el pago de la entidad a favor de la supervisión en un con- trato autofinanciado, supondría extender indebidamente dicho concepto. Esta última opinión no supone la creación de un nuevo supuesto de exclusión del concepto de cofi- nanciamiento, puesto que dicho pago no se encuentra enmarcado dentro de la regla ge- neral de dicho concepto."}

El MEF ha señalado en las Opiniones que, si durante la etapa de ejecución contractual en contratos de largo plazo se hace necesario actualizar o implementar nuevos acuerdos que involucren pagos por parte de la entidad pública titular del proyecto, evidenciado en la realización de inversiones adicionales, estas inversiones incluidas en el contrato mediante un procedimiento de modificación contractual constituyen "cofinanciamiento", sin que ello implique modificar la calificación de un proyecto originalmente autofinanciado.

Esto sin duda está operando en aquellas APP cuyo origen ha sido autofinanciado, como es el caso de las IP de EsSalud o municipales, en las que las inversiones adicionales están consideradas como cofinanciadas, ya que a criterio del MEF siempre lo fueron. ${ }^{12}$

11. Estas Opiniones serían vinculantes porque el MEF, al emitirlas, menciona su atribución de emitir opinión vinculante y excluyente, prevista en el numeral 4 del inciso 9.1 del artículo 9 del Decreto Legislativo 1362.

12. Ello se encuentra señalado en el Oficio Nº30-2019-EF-68.02 e Informe adjunto N² 271-2019-EF/68.02. 
2. Pertinencia de las opiniones previas a que se refiere el Decreto Legislativo 1362.

\section{Opinión vinculante: Oficio $\quad \mathrm{N}^{\circ}$ 004-2019-} EF/68.02.

El artículo 8 del Decreto Legislativo 1362 dispone que el Organismo Promotor de la Inversión Privada — OPIP es el encargado de la estructuración del proyecto de APP, y de diseñar, conducir y concluir el proceso de promoción y diseño de la Versión Inicial —VFI y Final —VFC del Contrato de APP, en las etapas de estructuración y transacción, respectivamente.

El artículo 50 del Reglamento establece que la OPIP deberá emitir la versión de cada contrato, el Informe de Evaluación Integrado - IEl, y el modelo económico financiero. En esta misma línea, el artículo 44 del Decreto, concordado con el artículo 55 de su Reglamento, establecen que se requiere obtener lo siguiente:

a) La opinión favorable de la entidad pública titular del proyecto en el marco de sus competencias.

b) La opinión no vinculante del organismo regulador, en el marco de sus competencias.

c) La opinión favorable del MEF.

d) El informe previo no vinculante de la Contraloría General de la República.

De acuerdo con el artículo 55 del Reglamento, el OPIP debe solicitar la opinión previa sobre las respectivas versiones del contrato tanto del organismo regulador como de la entidad titular del proyecto, siendo la primera de carácter obligatorio no vinculante, y la segunda de carácter obligatorio y vinculante, por cuanto esta última implica la viabilidad y continuidad del proyecto. La obligatoriedad de ambos pronunciamientos está referida a que es imperativo que el OPIP los solicite, mientras que la vinculatoriedad se refiere al cumplimiento necesario de los informes emitidos por alguna de las entidades.

El MEF ha señalado:

"Estas Opiniones no se refieren al IEl, sino a las versiones del contrato. Por ello, es posible formular modificaciones el IEI en atención a las opiniones formuladas por las entidades competentes, sin que resulte obligatorio por ello volver a solicitar las opiniones previas a la respectiva versión del contrato, si aquellas no contravienen el contenido de la misma."

\section{Proceso de modificación contractual y criterios para su procedencia.}

Opiniones vinculantes: Oficios $\mathrm{N}^{\circ}$ 005-2019$\mathrm{EF} / 68.02$, 012-2019-EF/68.02, 016-2019$E F / 68.02$, 006-2019-EF-68.02, y 021-2020$\mathrm{EF} / 68.02$-existen además los Oficios $\mathrm{N}^{\circ}$ 030-2019-EF/68.02 y 064-2020-EF/68.02, que, sin ser vinculantes, contienen un criterio de interpretación relevante sobre esta materia respecto a la entrada de un nuevo marco normativo sobre contratos de APP-.

Los artículos 134 al 138 del Reglamento del Decreto Legislativo 1362 están referidos a los procedimientos de modificación contractual, reconociéndose tres momentos importantes:

a) Evaluación conjunta: permite a la entidad pública titular del proyecto conocer las eventuales observaciones a la propuesta de adenda por parte de las entidades que emitirán opinión previa.

b) Evaluación y sustento de la propuesta de modificación contractual.

c) Solicitud de las opiniones previas a las siguientes entidades públicas: Proinversión, el organismo regulador, el MEF, y Contraloría General de la República; siendo la opinión del MEF la única vinculante en caso las modificaciones introduzcan cambios en materias de cofinanciamiento, garantías, equilibrio económico financiero del contrato de APP, contingencias fiscales del Estado, o parámetros económicos y financieros del contrato de APP. Por ser vinculante y obligatoria, no solo es necesario contar con la opinión del MEF, sino que esta debe ser favorable al proyecto de modificación.

Las circunstancias imprevistas que surgen en el marco de la fase de ejecución contractual pue- 
den requerir que las condiciones inicialmente pactadas sean actualizadas, teniendo por ello: actos de ejecución contractual expresamente señalados en el texto del contrato, o circunstancias no reguladas en el texto contractual.

El primer supuesto señalado no se constituye como una modificación contractual, conforme a lo establecido por el Decreto en su artículo 55 , puesto que los cambios ya se encuentran incluidos en el texto contractual inicial. En estos casos no se opta por la suscripción de una adenda, sino por la aplicación del mecanismo contractual predeterminado.

En caso se tratase del segundo supuesto, serán de aplicación los artículos 55 del Decreto y los artículos 134 al 138 de su Reglamento.

El MEF ha señalado que:

a) Para aplicar la solución propuesta por el Amigable Componedor, se requiere modificar el Contrato de APP, siguiendo el procedimiento de los artículos 134 al 138 del Reglamento, sin existir excepciones al cumplimiento de estas disposiciones. ${ }^{13}$

b) Las partes que no hubiesen pactado el uso del Amigable Componedor en el contrato de APP, deben hacer constar su acuerdo para tales efectos durante la etapa de Trato Directo. Sin perjuicio de lo anterior, de acuerdo al párrafo 56.2 del DL 1362, las partes de un contrato de APP pueden acudir al procedimiento del Amigable Componedor, incluso sin haberlo pactado en el contrato.

c) Al igual que con el proyecto de solución de controversias por el Amigable Componedor, para dar cumplimiento a lo dispuesto por un laudo arbitral que obligue al Estado peruano efectuar pagos por trabajos adicionales, es necesario que se siga el procedimiento de modificación contractual establecido anteriormente. En lo que concierne al caso de laudos arbitrales, se indica que la opinión que emitirá el MEF sobre el proyecto de adenda al contrato, estará referida a aquellos aspectos resueltos en el laudo arbitral que se encuentren dentro del margen de decisión de las partes del ADMINISTRATIVo contrato, tales como el modo o cantidad específica a ser reconocidos por los trabajos adicionales.

d) En caso se requieran modificaciones a un contrato como consecuencia del Trato Directo, incluso para solucionar controversias derivadas de la ejecución de un contrato de APP, éstas deberán ser incluidas mediante el procedimiento establecido en los artículos 134 al 138 del Reglamento del DL 1362.

e) Los contratos de APP no verán modificada su ejecución, ni los términos inicialmente pactados, por la entrada en vigencia de un nuevo marco normativo.

A este respecto, debemos comentar que no nos parece conveniente que se pretenda que lo que se resuelve mediante los mecanismos de solución de controversias del contrato de APP tenga que pasar por el procedimiento de celebración de adendas ya que se trata de decisiones irrevisables. Sin duda, deberían incorporarse a los contratos, pero no seguir el procedimiento de celebración de adendas.

\section{Naturaleza de las inversiones adicionales en un contrato de APP.}

\section{Opinión vinculante: Oficio $\quad \mathrm{N}^{\circ}$ 041-2019- $\mathrm{EF} / 68.02$.}

Para que una inversión sea considerada adicional, es necesario que esta: i) no haya sido considerada en el proyecto original del contrato, ii) se encuentre de alguna manera vinculada al proyecto, iii) que su relevancia haya sido deter-

13. Esta Opinión tiene que ser aplicada en consonancia con los "Lineamientos para el Diseño de Contratos de Asociación Público Privada", aprobados mediante Resolución Directoral № 001-2019-EF/68.01, que establecen que "no todo cambio en las condiciones del contrato debe materializarse mediante una modificación contractual" —esta anotación no es de autoría del MEF-. 
minada dentro de la fase de ejecución del contrato, y iv) que no tenga finalidad de subsanar errores de cálculo, de diseño o constructivos.

No deben confundirse las inversiones adicionales con los compromisos contingentes, contenidos en el mismo texto del contrato y referidos a las posibles obligaciones de pago por parte del Estado a favor de su contraparte contractual en caso los riesgos propios del proyecto de APP llegasen a materializarse. No corresponde a la norma determinar este tipo de obligaciones, sino al mismo texto del contrato.

En opinión del MEF, la incorporación y ejecución de inversiones adicionales debe adecuarse al procedimiento regular de modificación contractual, procediendo las partes a la suscripción de una adenda, la evaluación conjunta y la solicitud de opiniones de las entidades competentes, conforme a los dispuesto en los artículos 134 al 138 del Reglamento del DL 1362.

\section{Criterio para calificar a una entidad públi- ca como titular de un proyecto de APP.}

\section{Opinión vinculante: Oficio $\quad N^{\circ}$ 015-2019- $\mathrm{EF} / 68.02$.}

Para que una entidad pública asuma la titularidad de un proyecto bajo la modalidad de APP o PA, ésta requiere de una autorización expresa por parte de una norma con rango legal, conforme a lo establecido por el artículo 6 del Decreto Legislativo 1362. Para obtener esta autorización, la entidad pública debe tener facultad de administración y/o disposición de activos, no limitándose esta autorización a las entidades que conformen el Gobierno Nacional.

Bajo esta misma línea, el MEF ha señalado que en el actual marco normativo no existe la posibilidad de que haya dos entidades titulares de un mismo proyecto, por lo que corresponderá que las mismas entidades involucradas suscriban los acuerdos necesarios para la adecuada implementación del proyecto.

La normativa del Sistema Nacional de Promoción de la Inversión Privada dispone que los
OPIP se encarguen de diseñar, conducir y concluir el proceso de promoción de la inversión privada mediante las modalidades de APP y PA, dependiendo sus facultades del nivel de gobierno.

En el caso del Gobierno Nacional, el OPIP es Proinversión o los Ministerios, a través del Comité de Promoción de la Inversión Privada CPIP, en función al reglamento. En el caso de Gobiernos Regionales y Gobiernos Locales, el OPIP es el CPIP, cuyo órgano máximo es el Consejo Regional o Consejo Municipal.

El MEF ha dispuesto lo siguiente:

"Los proyectos bajo modalidad de APP o PA, en caso la entidad cuente con habilitación legal para realizar el proceso de promoción, deberán sujetar su ejecución a las disposiciones del Decreto Legislativo $N^{\circ} 1362$ y su Reglamento, referentes a la determinación del Organismo Promotor de la Inversión Privada, los cuales incluyen la posibilidad de encargar a Proinversión la conducción del proceso de promoción."

\section{Cesión de posición contractual en un contrato de concesión.}

Opinión vinculante: Oficio $\quad N^{\circ}$ 117-2019$\mathrm{EF} / 68.02$.

Conforme a lo establecido por el numeral 55.4 del artículo 55 del Decreto Legislativo 1362, las partes pueden convenir en la modificación del contrato de APP, manteniendo el equilibrio económico financiero, el valor por precio del contrato a favor del Estado, las condiciones de competencia del proceso de promoción, y procurando no afectar la asignación de riesgos, siguiendo además las reglas de evaluación y aprobación de las modificaciones contractuales conforme a la normativa del SNPIP.

El MEF ha señalado lo siguiente:

"La cesión de posición en un contrato de concesión sigue los lineamientos establecidos en los artículos 134 al 138 del Reglamento del 
Decreto Legislativo 1362 referidos al procedimiento de modificación contractual, incluso cuando sea emitida una Ley que obligue al concedente a ceder su posición a favor de otra entidad del Estado."

7. Naturaleza y trato normativo de la cláusula anticorrupción.

Opinión vinculante: Oficio $\mathrm{N}^{\circ}$ 010-2019-EF68.02.

El párrafo 39.1 del artículo 39 del Reglamento del DL 1362 dispone que todos los contratos de APP a ser suscritos por el Estado deben incluir una cláusula anticorrupción, bajo causal de nulidad. En este sentido, cuando ocurra la terminación del contrato por culpa imputable al inversionista derivado de la aplicación de la cláusula anticorrupción, no procede una indemnización por parte del Estado.

El MEF ha establecido que, si bien la inclusión de la cláusula anticorrupción se constituye como un requisito de validez al momento de suscripción del contrato, su no incorporación en el caso de modificaciones al contrato no tiene la misma calidad, y por ello no está sancionada con nulidad.

8. Modificaciones a la Iniciativa Privada y al cómputo de plazos previos a la opinión de relevancia.

Opinión vinculante: Oficio $\mathrm{N}^{\circ}$ 022-2019$E F / 68.02$.

El artículo 79 del Reglamento del DL 1362 dispone que la opinión de relevancia de la Iniciativa Privada es emitida por el titular del Ministerio, por acuerdo del Consejo Regional, acuerdo del Concejo Municipal o por el titular de las entidades públicas habilitadas mediante ley expresa -EPTP, y tienen carácter vinculante para el OPIP respecto a la continuación de su trámite.

El artículo 83 del mismo Reglamento establece que el OPIP puede proponer modificaciones que se consideren convenientes y/o necesarias en el contenido y diseño de la Iniciativa Privada
—IP, en cualquier fase, sea a pedido de la EPTP o por iniciativa propia, contando previamente con la opinión de la EPTP.

En consecuencia, en opinión del MEF: cido para la emisión de la opinión de relevancia, se soliciten modificaciones a la Iniciativa Privada presentada.

b) La suspensión del cómputo de plazo para la emisión de opinión de relevancia a la que está referida el numeral 79.4 del Reglamento también resulta aplicable para los supuestos en que el OPIP proponga ampliaciones y modificaciones, puesto que estas tienen la finalidad de confirmar $\mathrm{si}$, desde el punto de vista del proponente, resulta económica y técnicamente la realización de dichas modificaciones.

9. Las funciones de Proinversión ante el encargo del Proceso de Promoción de un proyecto aún no incorporado en el Informe Multianual de Inversiones en Asociaciones Público Privadas.

Opinión vinculante: Oficio $\mathrm{N}^{\circ}$ 025-2019$E F / 68.02$.

Los proyectos ejecutados bajo la modalidad de APP, independientemente de su clasificación y origen, se desarrollan, de conformidad con el artículo 30 del Decreto Legislativo 1362, en las siguientes fases: i) Planeamiento y Programación, que comprende la planificación de proyectos y de los compromisos, firmes y contingentes, derivados de la suscripción de contratos de APP, y se materializa en el Informe Multianual de Inversiones en Asociaciones Público Privadas; ii) Formulación, que comprende el diseño y/o evaluación del proyecto, a fin de elaborar el Informe de Evaluación, y concluye con la aprobación del mismo; iii) Estructuración y Transacción; y iv) Ejecución Contractual.

El artículo 42 del Reglamento dispone que, cuando Proinversión participa como OPIP, es responsable de la elaboración del Informe de Evaluación. En este caso, corresponde a la enti- 
dad titular del proyecto desarrollar los estudios técnicos, pudiendo encargar su elaboración y/o contratación a Proinversión.

En opinión del MEF, el encargo de estudios técnicos o la elaboración del informe a Proinversión no requiere que previamente el proyecto haya sido incorporado dentro el Informe Multianual de Inversiones en Asociaciones Público Privadas de la entidad pública titular del proyecto.

\section{Los alcances del informe previo de la Contraloría General de la República en las fases de estructuración y transacción de un contrato de APP.}

Opinión vinculante: Oficio $\mathrm{N}^{\circ}$ 034-2019$\mathrm{EF} / 68.02$.

El informe de la Contraloría General de la República, en cuanto a las versiones del contrato de APP, se caracteriza por ser no vinculante, de conformidad con el artículo 41 del Decreto Legislativo 1362 y al artículo 55 de su Reglamento.

Conforme a la opinión del MEF, contar con el informe previo de esta entidad con respecto a la VFC, solo será obligatorio para el OPIP si es que la versión del contrato incluye aspectos que comprometan el crédito o la capacidad financiera del Estado, y que, además, estén relacionados con el cofinanciamiento o las garantías del proyecto.

Bajo esta misma línea, el artículo 22 de la Ley 27785, Ley Orgánica del Sistema de Control y de la Contraloría General de la República le atribuye a la referida entidad: i) competencia para emitir opinión en proyectos de contrato en los que una de las partes sea el Estado, y ii) esta competencia se rige por un conjunto de temas taxativos, es decir, solo cuando se com- prometa el crédito o capacidad financiera del Estado.

\section{CONCLUSIONES}

La DGPPIP del MEF ha ejercido como rector la función de emitir opinión exclusiva y excluyente con carácter vinculante sobre el alcance de las normas del SNPIP de su competencia.

Solo 15 de esas opiniones contienen propiamente una interpretación vinculante para todos los actores del SNPIP respecto del Decreto Legislativo 1362 y su reglamento y están identificadas y consignadas en este artículo.

Las demás han sido emitidas sin cumplir los requisitos legales para su procedencia, principalmente porque las entidades que consultaron a la DGPPIP lo hicieron aludiendo a casos específicos en los que les tocaba adoptar decisiones de gestión, que es un supuesto negado para la viabilidad legal de una interpretación normativa según los Criterios Generales para la atención de Consultas Técnico Normativas en materia de APP y PA.

Las opiniones en estos casos se han justificado en los principios de "colaboración entre entidades", "adecuado servicio al ciudadano" y "predictibilidad". Sin embargo, ha sido inadecuado que la DGPPIP emita esas opiniones porque influyen en las decisiones de gestión, que es responsabilidad de cada entidad pública en el marco del SNPIP; y muchas veces las condicionan, ya que la misma DGPPIP emite opinión vinculante en diversas etapas de las APP y el Sistema de Control toma estas interpretaciones como parámetro de evaluación de responsabilidad. Por lo tanto, concluimos en este artículo que el MEF solo debe responder las solicitudes de interpretación vinculante que cumplen los Criterios Generales para la atención de Consultas Técnico Normativas en materia de APP y PA. 


\begin{tabular}{|c|c|c|c|c|c|c|}
\hline $\begin{array}{l}\text { Disposición } \\
\text { Normativa }\end{array}$ & Oficios & $\begin{array}{l}\text { Infor- } \\
\text { mes }\end{array}$ & Fecha & Motivo & Materia & $\begin{array}{l}\text { Numeral del } \\
\text { Informe de la } \\
\text { interpretación }\end{array}$ \\
\hline \multicolumn{7}{|c|}{ DECRETO LEGISLATIVO 1362 Y SU REGLAMENTO —EN CONJUNTO—- } \\
\hline $\begin{array}{l}\text { Artículo } 4 \\
\text { del Decreto } \\
\text { Legislativo } \\
1362 \text { y } \\
\text { artículo } \\
111 \text { de su } \\
\text { Reglamento. } \\
\text { Resolución } \\
\text { Ministerial } \\
N^{\circ} 167-2016- \\
\text { EF/15 }\end{array}$ & $\begin{array}{l}063- \\
2020- \\
E F / 68.02\end{array}$ & $\begin{array}{l}069- \\
2020- \\
E F / 68.02\end{array}$ & $\begin{array}{l}26 / 05 / \\
2020\end{array}$ & $\begin{array}{l}\text { Interpretación } \\
\text { por el } \\
\text { principio de } \\
\text { colaboración } \\
\text { entre } \\
\text { entidades. }\end{array}$ & $\begin{array}{l}\text { Efectos de la "Ley } \\
\text { y Disposiciones } \\
\text { aplicables" como } \\
\text { evento de fuerza } \\
\text { mayor, según lo } \\
\text { señalado en los } \\
\text { "Lineamientos } \\
\text { para la Asignación } \\
\text { de Riesgos en } \\
\text { los Contratos de } \\
\text { Asociaciones Público } \\
\text { Privadas", en el } \\
\text { contexto del brote } \\
\text { de la COVID-19 y } \\
\text { las normas emitido } \\
\text { a fin de evitar su } \\
\text { propagación. }\end{array}$ & $\begin{array}{l}\text { Numeral } 4 \\
\text { del Decreto } \\
\text { Legislativo: } \\
\text { apartado } 2.9 . \\
\text { Resolución } \\
\text { Ministerial No } \\
\text { 167-2016-EF/15: } \\
\text { apartado 2.10. } \\
\text { Artículo } 111 \text { del } \\
\text { Reglamento: } \\
\text { apartado } 2.11 . \\
\text { Artículo } 37 \text { del } \\
\text { Reglamento } \\
\text { apartado 2.12. }\end{array}$ \\
\hline $\begin{array}{l}\text { Artículo } 6 \\
\text { del Decreto } \\
\text { Legislativo } \\
1362 \text { y } \\
\text { artículos } 13 \\
\text { al } 15 \text { de su } \\
\text { Reglamento. }\end{array}$ & $\begin{array}{l}015- \\
2019- \\
E F / 68.02\end{array}$ & $\begin{array}{l}147- \\
2019- \\
E F / 68.02\end{array}$ & $\begin{array}{l}14 / 05 / \\
2019\end{array}$ & $\begin{array}{l}\text { No aplica } \\
\text { colaboración } \\
\text { entre } \\
\text { entidades. }\end{array}$ & $\begin{array}{l}\text { Habilitación como } \\
\text { entidad pública } \\
\text { titular de proyecto } \\
\text { y Organismo } \\
\text { Promotor de la } \\
\text { Inversión Privada. }\end{array}$ & $\begin{array}{l}\text { Artículo } 13 \text { y } 15 \\
\text { del Reglamento: } \\
\text { apartado } 2.14 \text {. } \\
\text { Mención al artículo } \\
6 \text { del Decreto } \\
\text { Legislativo: } \\
\text { apartado } 2.8 \text {. }\end{array}$ \\
\hline $\begin{array}{l}\text { Artículos } \\
11,13.2, \\
18.2 \text { y } 41 \\
\text { del Decreto } \\
\text { Legislativo } \\
1362 ; \text { y } \\
\text { artículos } 50 \\
\text { y } 55 \text { de su } \\
\text { Reglamento. }\end{array}$ & $\begin{array}{l}004- \\
2019- \\
E F / 68.02\end{array}$ & $\begin{array}{l}031- \\
2019- \\
E F / 68.02\end{array}$ & $\begin{array}{l}11 / 02 / \\
2019\end{array}$ & $\begin{array}{l}\text { No aplica } \\
\text { colaboración } \\
\text { entre } \\
\text { entidades. }\end{array}$ & $\begin{array}{l}\text { Opiniones previas } \\
\text { en caso de } \\
\text { modificación de } \\
\text { las versiones de } \\
\text { contrato y del IEl. }\end{array}$ & $\begin{array}{l}\text { Artículo } 11 \text { del Decreto } \\
\text { Legislativo: apartado } 2.32 . \\
\text { Artículo } 13.2 \text { del Decreto } \\
\text { Legislativo: apartado } 2.33 \text {. } \\
\text { Artículo } 41 \text { del Decreto } \\
\text { Legislativo: apartado } 2.34 \text {. } \\
\text { Artículo } 18.2 \text { del Decreto } \\
\text { Legislativo: apartado } 2.35 . \\
\text { Artículo } 50 \text { del Reglamento: } \\
\text { apartado } 2.20 \text {. } \\
\text { Artículo } 55 \text { del Reglamento: } \\
\text { apartado } 2.29 \text {. }\end{array}$ \\
\hline
\end{tabular}




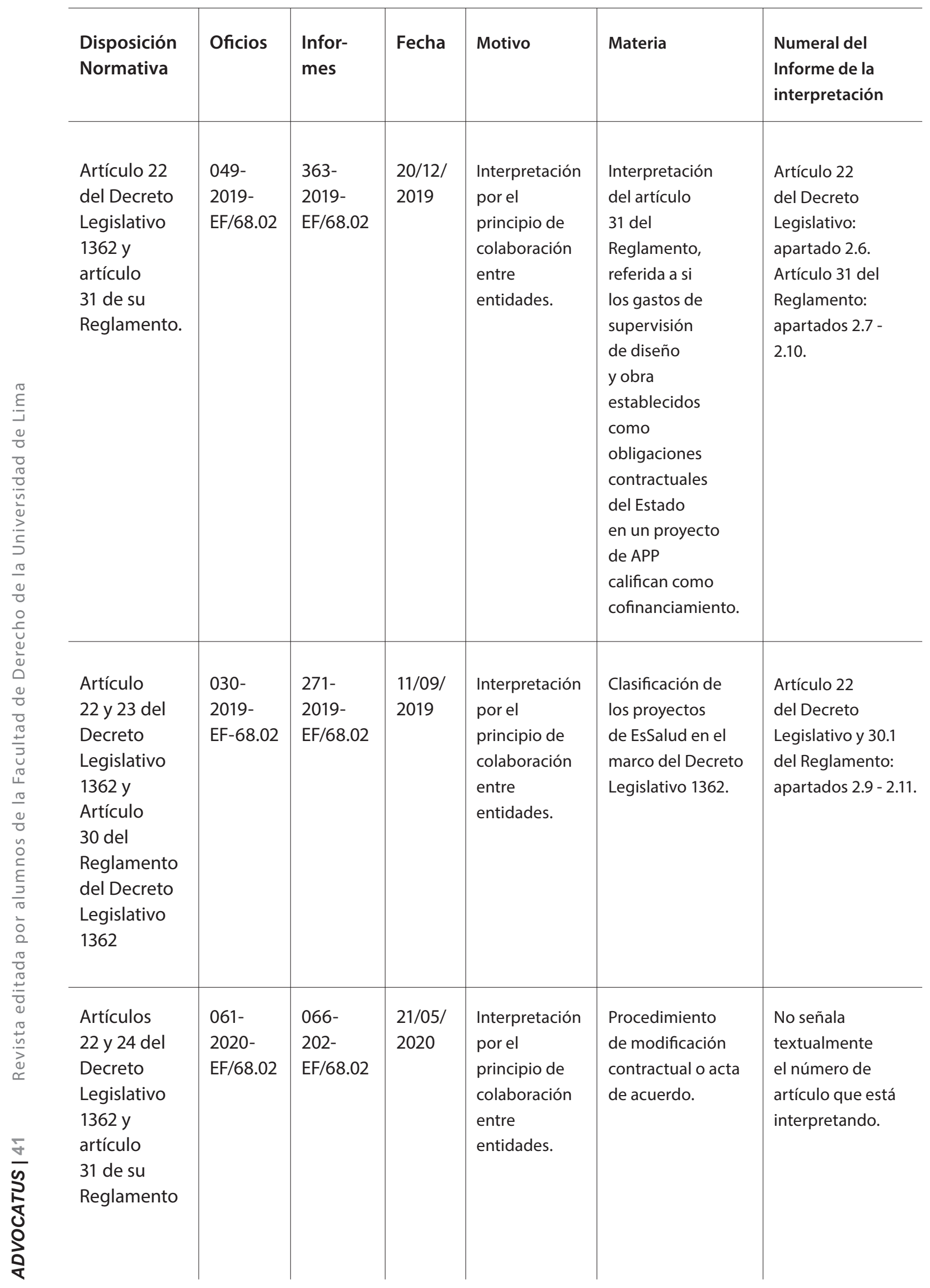




\begin{tabular}{|c|c|c|c|c|c|c|c|}
\hline $\begin{array}{l}\text { Disposición } \\
\text { Normativa }\end{array}$ & Oficios & $\begin{array}{l}\text { Infor- } \\
\text { mes }\end{array}$ & Fecha & Motivo & Materia & $\begin{array}{l}\text { Numeral del } \\
\text { Informe de la } \\
\text { interpretación }\end{array}$ & $\sqrt{18}$ \\
\hline $\begin{array}{l}\text { Artículos } \\
22 \text { y } 24 \text { del } \\
\text { Decreto } \\
\text { Legislativo } \\
1362 \text { y } \\
\text { artículo } \\
31 \text { de su } \\
\text { Reglamento. }\end{array}$ & $\begin{array}{l}004- \\
2020- \\
E F / 68.02\end{array}$ & $\begin{array}{l}024- \\
2020- \\
E F / 68.02\end{array}$ & $\begin{array}{l}3 / 02 \\
2020\end{array}$ & $\begin{array}{l}\text { Se desarrolla } \\
\text { de "oficio" la } \\
\text { interpretación. }\end{array}$ & $\begin{array}{l}\text { Consulta sobre } \\
\text { si pago de la } \\
\text { supervisión de las } \\
\text { inversiones } \\
\text { —diseño } \\
\text { y obra- } \\
\text { califica como } \\
\text { cofinanciamiento. }\end{array}$ & $\begin{array}{l}\text { Artículo } 22 \\
\text { del Decreto } \\
\text { Legislativo: } \\
\text { apartado } 18 . \\
\text { Artículo } 24 \\
\text { del Decreto } \\
\text { Legislativo: } \\
\text { apartado } 16 . \\
\text { Artículo } 31 \text { del } \\
\text { Reglamento: } \\
\text { apartados } \\
19 \text { - } 23 .\end{array}$ & $\begin{array}{c}\text { DERECHO } \\
\text { ADMINISTRATIVO }\end{array}$ \\
\hline $\begin{array}{l}\text { Párrafo } \\
38.2 \text { del } \\
\text { Artículo } 38 \\
\text { del Decreto } \\
\text { Legislativo } \\
1362\end{array}$ & $\begin{array}{l}029- \\
2019- \\
\text { EF-68.02 }\end{array}$ & $\begin{array}{l}270- \\
2019- \\
E F / 68.02\end{array}$ & $\begin{array}{l}11 / 09 / \\
2019\end{array}$ & $\begin{array}{l}\text { Interpretación } \\
\text { por el } \\
\text { principio de } \\
\text { colaboración } \\
\text { entre } \\
\text { entidades. }\end{array}$ & $\begin{array}{l}\text { Renovación } \\
\text { contractual de } \\
\text { los Contratos } \\
\text { de Asociaciones } \\
\text { Público Privadas. }\end{array}$ & $\begin{array}{l}\text { Artículo } 55 \\
\text { del Decreto } \\
\text { Legislativo: } \\
\text { apartado 2.10. }\end{array}$ & \\
\hline $\begin{array}{l}\text { Artículo } 40 \\
\text { del Decreto } \\
\text { Legislativo } \\
1362 .\end{array}$ & $\begin{array}{l}019- \\
2019- \\
E F / 68.02\end{array}$ & $\begin{array}{l}190- \\
2019- \\
E F / 68.02\end{array}$ & $\begin{array}{l}19 / 06 / \\
2019\end{array}$ & $\begin{array}{l}\text { Interpretación } \\
\text { por el } \\
\text { principio de } \\
\text { colaboración } \\
\text { entre } \\
\text { entidades. }\end{array}$ & $\begin{array}{l}\text { Aprobación del } \\
\text { Informe Multianual } \\
\text { de Inversiones en } \\
\text { APP. }\end{array}$ & $\begin{array}{l}\text { Artículo } 40.2 \\
\text { del Reglamento: } \\
\text { apartado } 2.8 \text {. } \\
\text { Artículo } 40.7 \text { del } \\
\text { Reglamento: } \\
\text { apartados } 2.9 \text { - } \\
2.11 \text {. }\end{array}$ & \\
\hline $\begin{array}{l}\text { Artículo } 41 \\
\text { del Decreto } \\
\text { Legislativo } \\
1362 \text { y } \\
\text { artículo } \\
55 \text { de su } \\
\text { Reglamento. }\end{array}$ & $\begin{array}{l}034- \\
2019- \\
E F / 68.02\end{array}$ & $\begin{array}{l}288- \\
2019- \\
E F / 68.02\end{array}$ & $\begin{array}{l}25 / 09 / \\
2019\end{array}$ & $\begin{array}{l}\text { No aplica } \\
\text { colaboración } \\
\text { entre } \\
\text { entidades. }\end{array}$ & $\begin{array}{l}\text { Interpretación } \\
\text { del artículo } 41 \text { del } \\
\text { Decreto Legislativo } \\
1362 \text { sobre el } \\
\text { Informe previo } \\
\text { de la Contraloría } \\
\text { General de la } \\
\text { República. }\end{array}$ & $\begin{array}{l}\text { Artículo } 41 \text { del } \\
\text { Decreto Legislativo } \\
\text { y artículo } 55 \text { del } \\
\text { Reglamento: } \\
\text { apartado 3.1. }\end{array}$ & \\
\hline
\end{tabular}




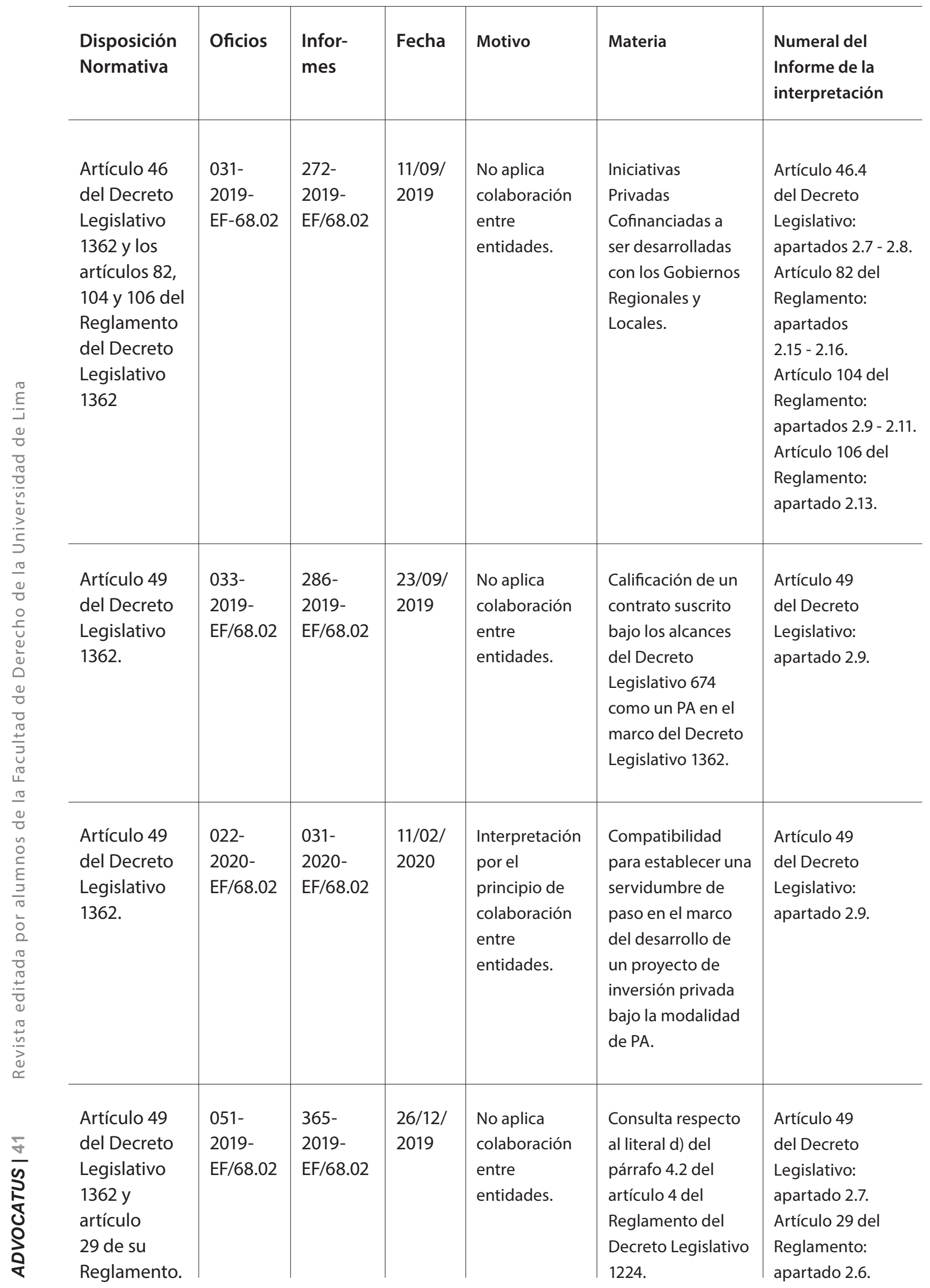




\begin{tabular}{|c|c|c|c|c|c|c|c|}
\hline $\begin{array}{l}\text { Disposición } \\
\text { Normativa }\end{array}$ & Oficios & $\begin{array}{l}\text { Infor- } \\
\text { mes }\end{array}$ & Fecha & Motivo & Materia & $\begin{array}{l}\text { Numeral del } \\
\text { Informe de la } \\
\text { interpretación }\end{array}$ & $\frac{1}{18}$ \\
\hline $\begin{array}{l}\text { Artículo } 52 \\
\text { y Séptima } \\
\text { Disposición } \\
\text { Complemen- } \\
\text { taria Final } \\
\text { del Decreto } \\
\text { Legislativo } \\
1362 .\end{array}$ & $\begin{array}{l}062- \\
2020- \\
E F / 68.02\end{array}$ & $\begin{array}{l}\text { 068- } \\
2020- \\
E F / 68.02\end{array}$ & $\begin{array}{l}26 / 05 / \\
2020\end{array}$ & $\begin{array}{l}\text { No aplica } \\
\text { colaboración } \\
\text { entre } \\
\text { entidades. }\end{array}$ & $\begin{array}{l}\text { Modificación } \\
\text { contractual para } \\
\text { ampliar el plazo } \\
\text { de la concesión } \\
\text { de un contrato de } \\
\text { infraestructura } \\
\text { portuaria } \\
\text { —-suscrito bajo } \\
\text { la normativa del } \\
\text { Decreto Supremo } \\
\mathrm{N}^{\circ} 059-96-\mathrm{PCM}-\text {. }\end{array}$ & $\begin{array}{l}\text { Artículo } 52 \\
\text { del Decreto } \\
\text { Legislativo: } \\
\text { apartado 3.1. } \\
\text { Séptima } \\
\text { Disposición } \\
\text { Complementaria } \\
\text { Final del Decreto } \\
\text { Legislativo: } \\
\text { apartado 2.8. }\end{array}$ & $\begin{array}{c}\text { DERECHO } \\
\text { ADMINISTRATIVO }\end{array}$ \\
\hline $\begin{array}{l}\text { Artículo } 55 \\
\text { del Decreto } \\
\text { Legislativo } \\
1362 \text { y } \\
\text { artículos } \\
109,134,136 \\
\text { y } 138 \text { de su } \\
\text { Reglamento. }\end{array}$ & $\begin{array}{l}047- \\
2019- \\
E F / 68.02\end{array}$ & $\begin{array}{l}354- \\
2019- \\
E F / 68.02\end{array}$ & $\begin{array}{l}17 / 12 / \\
2019\end{array}$ & $\begin{array}{l}\text { Interpretación } \\
\text { por el } \\
\text { principio de } \\
\text { colaboración } \\
\text { entre } \\
\text { entidades. }\end{array}$ & $\begin{array}{l}\text { Consulta } \\
\text { relacionada a } \\
\text { la renovación } \\
\text { contractual del } \\
\text { contrato de APP. }\end{array}$ & $\begin{array}{l}\text { Artículo } 55 \text { del } \\
\text { Decreto Legislativo } \\
\text { y Artículos } 109, \\
134,136 \text { y } 138 \\
\text { del Reglamento: } \\
\text { apartado } 2.7 \text {. }\end{array}$ & \\
\hline $\begin{array}{l}\text { Artículo } 55 \\
\text { del Decreto } \\
\text { Legislativo } \\
1362 \text { y } \\
\text { artículos } 134 \\
\text { al } 138 \text { de su } \\
\text { Reglamento. }\end{array}$ & $\begin{array}{l}064- \\
2020- \\
E F / 68.02\end{array}$ & $\begin{array}{l}071- \\
2020- \\
E F / 68.02\end{array}$ & $\begin{array}{l}6 / 06 \\
2020\end{array}$ & $\begin{array}{l}\text { Interpretación } \\
\text { por el } \\
\text { principio de } \\
\text { colaboración } \\
\text { entre } \\
\text { entidades. }\end{array}$ & $\begin{array}{l}\text { Reglas para } \\
\text { evaluación y } \\
\text { pertinencia de } \\
\text { la suscripción de } \\
\text { actas de acuerdo } \\
\text { como instrumento } \\
\text { que permite } \\
\text { implementar } \\
\text { supuestos } \\
\text { contractuales } \\
\text { previamente } \\
\text { pactados en el } \\
\text { contrato de APP } \\
\text { - aplazamiento } \\
\text { de la oportunidad } \\
\text { de pago de la } \\
\text { retribución hasta } \\
\text { mitigar los efectos } \\
\text { de fuerza mayor- }\end{array}$ & $\begin{array}{l}\text { Artículo } 55 \\
\text { del Decreto } \\
\text { Legislativo: } \\
\text { apartados } \\
2.10 \text { y } 2.13 . \\
\text { Artículo } 138 \text { del } \\
\text { Reglamento: } \\
\text { apartados } 2.17 \text { y } \\
2.22 \text {. }\end{array}$ & 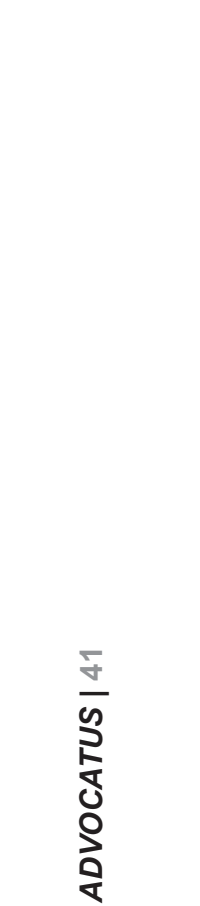 \\
\hline
\end{tabular}




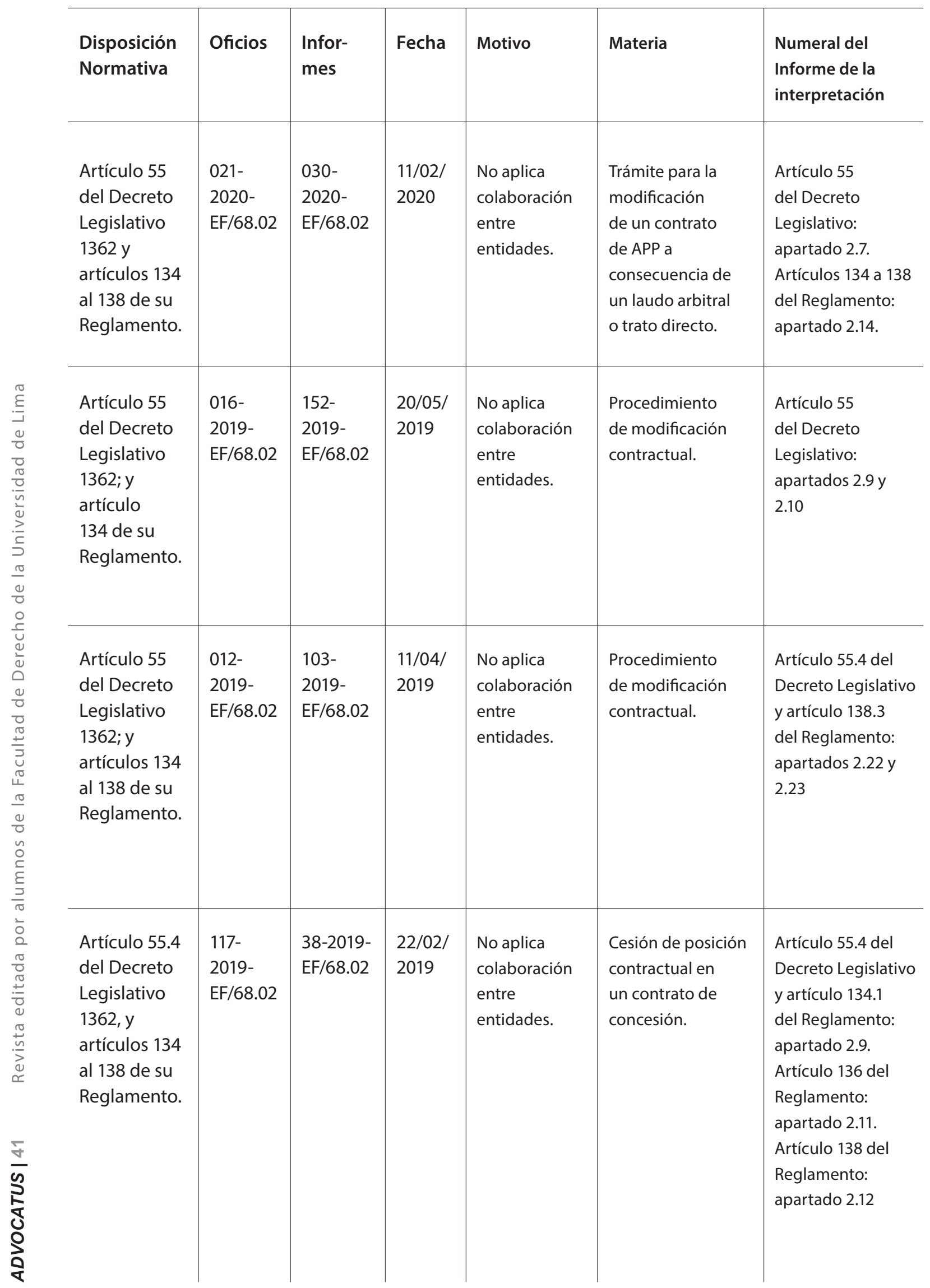




\begin{tabular}{|c|c|c|c|c|c|c|c|}
\hline $\begin{array}{l}\text { Disposición } \\
\text { Normativa }\end{array}$ & Oficios & $\begin{array}{l}\text { Infor- } \\
\text { mes }\end{array}$ & Fecha & Motivo & Materia & $\begin{array}{l}\text { Numeral del } \\
\text { Informe de la } \\
\text { interpretación }\end{array}$ & $\frac{\mathbf{U}}{\mathbf{U}}$ \\
\hline $\begin{array}{l}\text { Artículo } 55.6 \\
\text { del Decreto } \\
\text { Legislativo } \\
1362, \text { y artí- } \\
\text { culo } 138.8 \text { de } \\
\text { su Regla- } \\
\text { mento. }\end{array}$ & $\begin{array}{l}048- \\
2018- \\
E F / 68.02\end{array}$ & $\begin{array}{l}313- \\
2018- \\
E F / 68.02\end{array}$ & $\begin{array}{l}26 / 12 / \\
2018\end{array}$ & $\begin{array}{l}\text { No aplica } \\
\text { colaboración } \\
\text { entre } \\
\text { entidades. }\end{array}$ & $\begin{array}{l}\text { Supuestos en los } \\
\text { que la Contraloría } \\
\text { General de } \\
\text { la República } \\
\text { se encuentra } \\
\text { habilitada para } \\
\text { emitir Informe } \\
\text { Previo en un } \\
\text { procedimiento } \\
\text { de modificación } \\
\text { contractual. }\end{array}$ & $\begin{array}{l}\text { Artículo } 55 \\
\text { del Decreto } \\
\text { Legislativo: } \\
\text { apartado 5.2. }\end{array}$ & $\begin{array}{c}\text { DERECHO } \\
\text { ADMINISTRATIVO }\end{array}$ \\
\hline $\begin{array}{l}\text { Artículo } 56.2 \\
\text { del Decreto } \\
\text { Legislativo } \\
1362 .\end{array}$ & $\begin{array}{l}006- \\
2019- \\
\text { EF-68.02 }\end{array}$ & $\begin{array}{l}047- \\
2019- \\
E F / 68.02\end{array}$ & $\begin{array}{l}20 / 02 / \\
2019\end{array}$ & $\begin{array}{l}\text { No aplica } \\
\text { colaboración } \\
\text { entre } \\
\text { entidades. }\end{array}$ & $\begin{array}{l}\text { Uso del Amigable } \\
\text { Componedor. }\end{array}$ & $\begin{array}{l}\text { Artículo } 55.6 \text { del } \\
\text { Decreto Legislativo } \\
\text { y artículo } 119.1 \\
\text { del Reglamento: } \\
\text { apartado 3.1. }\end{array}$ & \\
\hline $\begin{array}{l}\text { Artículo } 57 \\
\text { del Decreto } \\
\text { Legislativo } \\
1362 \text { y } \\
\text { artículo } \\
118.2 \text { de su } \\
\text { Reglamento. }\end{array}$ & $\begin{array}{l}040- \\
2019- \\
E F / 68.02\end{array}$ & $\begin{array}{l}322- \\
2019- \\
E F / 68.02\end{array}$ & $\begin{array}{l}17 / 10 / \\
2019\end{array}$ & $\begin{array}{l}\text { Interpretación } \\
\text { por el } \\
\text { principio de } \\
\text { colaboración } \\
\text { entre } \\
\text { entidades. }\end{array}$ & $\begin{array}{l}\text { Selección y } \\
\text { contratación de la } \\
\text { supervisión en los } \\
\text { contratos de APP. }\end{array}$ & $\begin{array}{l}\text { Artículo } 57 \\
\text { del Decreto } \\
\text { Legislativo: } \\
\text { apartado } 2.17 . \\
\text { Artículo } 118.2 \\
\text { del Reglamento: } \\
\text { apartado } 2.18 .\end{array}$ & \\
\hline \multicolumn{7}{|c|}{ REGLAMENTO —APROBADO MEDIANTE DECRETO SUPREMO Nº 240-2018-EF- } & \\
\hline $\begin{array}{l}\text { Artículo } 31 \\
\text { del Regla- } \\
\text { mento del } \\
\text { Decreto Legis- } \\
\text { lativo } 1362 .\end{array}$ & $\begin{array}{l}032- \\
2019- \\
\text { EF-68.02 }\end{array}$ & $\begin{array}{l}273- \\
2019- \\
E F / 68.02\end{array}$ & $\begin{array}{l}11 / 09 / \\
2019\end{array}$ & $\begin{array}{l}\text { Interpretación } \\
\text { por brindar } \\
\text { un adecuado } \\
\text { servicio al } \\
\text { ciudadano. }\end{array}$ & $\begin{array}{l}\text { Recursos de las } \\
\text { entidades que } \\
\text { califican como } \\
\text { cofinanciamiento. }\end{array}$ & $\begin{array}{l}\text { Artículo } 31 \text { del } \\
\text { Reglamento: } \\
\text { apartado } 2.10 .\end{array}$ & \\
\hline $\begin{array}{l}\text { Artículo } 39.1 \\
\text { del Regla- } \\
\text { mento del } \\
\text { Decreto Legis- } \\
\text { lativo } 1362 .\end{array}$ & $\begin{array}{l}010- \\
2019- \\
\text { EF-68.02 }\end{array}$ & $\begin{array}{l}076- \\
2019- \\
E F / 68.02\end{array}$ & $\begin{array}{l}13 / 03 / \\
2019\end{array}$ & $\begin{array}{l}\text { No aplica } \\
\text { colaboración } \\
\text { entre } \\
\text { entidades. }\end{array}$ & $\begin{array}{l}\text { Inclusión de la } \\
\text { cláusula antico- } \\
\text { rrupción en los } \\
\text { contratos de } \\
\text { concesión, bajo } \\
\text { causal de nulidad. }\end{array}$ & $\begin{array}{l}\text { Artículo } 39.1 \text { del } \\
\text { Reglamento: } \\
\text { apartado 3.1. }\end{array}$ & 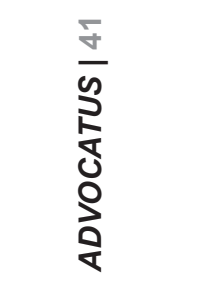 \\
\hline
\end{tabular}




\begin{tabular}{|c|c|c|c|c|c|c|}
\hline $\begin{array}{l}\text { Disposición } \\
\text { Normativa }\end{array}$ & Oficios & $\begin{array}{l}\text { Infor- } \\
\text { mes }\end{array}$ & Fecha & Motivo & Materia & $\begin{array}{l}\text { Numeral del } \\
\text { Informe de la } \\
\text { interpretación }\end{array}$ \\
\hline $\begin{array}{l}\text { Párrafo } 40.9 \\
\text { del Artículo } \\
40 \text { del } \\
\text { Reglamento } \\
\text { del Decreto } \\
\text { Legislativo } \\
1362 .\end{array}$ & $\begin{array}{l}025- \\
2019- \\
E F / 68.02\end{array}$ & $\begin{array}{l}252- \\
2019- \\
E F / 68.02\end{array}$ & $\begin{array}{l}8 / 08 / \\
2019\end{array}$ & $\begin{array}{l}\text { No aplica } \\
\text { colaboración } \\
\text { entre } \\
\text { entidades. }\end{array}$ & $\begin{array}{l}\text { Posibilidad de en- } \\
\text { cargar a Proinver- } \\
\text { sión la conducción } \\
\text { del Proceso de } \\
\text { Promoción de un } \\
\text { proyecto que aún } \\
\text { no se encuentra } \\
\text { incorporado en el } \\
\text { Informe Multianual } \\
\text { de Inversiones en } \\
\text { APP. }\end{array}$ & $\begin{array}{l}\text { Artículo } 40.9 \text { del } \\
\text { Reglamento: } \\
\text { apartado } 2.19 .\end{array}$ \\
\hline $\begin{array}{l}\text { Artículos } \\
79 \text { y } 83 \text { del } \\
\text { Reglamento } \\
\text { del Decreto } \\
\text { Legislativo } \\
1362 .\end{array}$ & $\begin{array}{l}022- \\
2019- \\
E F / 68.02\end{array}$ & $\begin{array}{l}221- \\
2019- \\
E F / 68.02\end{array}$ & $\begin{array}{l}18 / 07 / \\
2019\end{array}$ & $\begin{array}{l}\text { No aplica } \\
\text { colaboración } \\
\text { entre } \\
\text { entidades. }\end{array}$ & $\begin{array}{l}\text { Modificaciones a la } \\
\text { Iniciativa Privada } \\
\text { y al cómputo del } \\
\text { plazo si estas } \\
\text { ocurrieran antes } \\
\text { de la opinión de } \\
\text { relevancia. }\end{array}$ & $\begin{array}{l}\text { Artículo } 79.2 \text { del } \\
\text { Reglamento: } \\
\text { apartado } 2.12 \\
\text { Artículo } 83 \text { del } \\
\text { Reglamento: } \\
\text { apartados } 2.7 \text { y } 2.8 \text {. }\end{array}$ \\
\hline $\begin{array}{l}\text { Artículos } 134 \\
\text { al } 138 \text { del } \\
\text { Reglamento } \\
\text { del Decreto } \\
\text { Legislativo } \\
1362 .\end{array}$ & $\begin{array}{l}005- \\
2019- \\
E F / 68.02\end{array}$ & $\begin{array}{l}036- \\
2019- \\
E F / 68.02\end{array}$ & $\begin{array}{l}18 / 02 / \\
2019\end{array}$ & $\begin{array}{l}\text { No aplica } \\
\text { colaboración } \\
\text { entre } \\
\text { entidades. }\end{array}$ & $\begin{array}{l}\text { Procedimiento } \\
\text { de modificación } \\
\text { contractual. }\end{array}$ & $\begin{array}{l}\text { Artículos } 134 \text { a } 138 \\
\text { del Reglamento: } \\
\text { apartado 3.1. }\end{array}$ \\
\hline $\begin{array}{l}\text { Artículo } \\
137 \text { del } \\
\text { Reglamento } \\
\text { del Decreto } \\
\text { Legislativo } \\
1362 .\end{array}$ & $\begin{array}{l}041- \\
2019- \\
E F / 68.02\end{array}$ & $\begin{array}{l}324- \\
2019- \\
E F / 68.02\end{array}$ & $\begin{array}{l}22 / 10 / \\
2019\end{array}$ & $\begin{array}{l}\text { No aplica } \\
\text { colaboración } \\
\text { entre } \\
\text { entidades. }\end{array}$ & $\begin{array}{l}\text { Interpretación } \\
\text { y aplicación de } \\
\text { los alcances del } \\
\text { artículo } 137.1 \text { del } \\
\text { Reglamento sobre } \\
\text { reglas aplicables } \\
\text { para la evaluación } \\
\text { de modificaciones } \\
\text { contractuales, en } \\
\text { particular en lo } \\
\text { que se refiere a la } \\
\text { introducción de } \\
\text { inversiones adicio- } \\
\text { nales al proyecto. }\end{array}$ & $\begin{array}{l}\text { Artículo } 137 \text { del } \\
\text { Reglamento: } \\
\text { apartado } 3.5 .\end{array}$ \\
\hline
\end{tabular}

